\title{
Avaliação da atividade antimicrobiana de adesivo ortodôntico associado a verniz de clorexidina e timol na colagem de braquetes
}

\author{
Carolina Freire de Carvalho Calabrich*, Marcelo de Castellucci e Barbosa**,

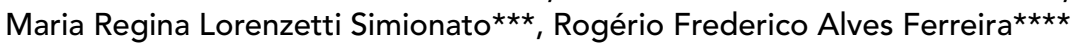

\begin{abstract}
Resumo
Objetivo: avaliar a atividade antimicrobiana da associação de um adesivo ortodôntico com um verniz de clorexidina e timol. Métodos: foram utilizados 32 pré-molares humanos divididos em 4 grupos. $\mathrm{O}$ grupo 1 consistiu do grupo controle, no qual o adesivo utilizado para a colagem do braquete não estava associado a nenhum agente antimicrobiano. Os grupos 2, 3 e 4 foram colados com um sistema adesivo associado a um verniz de clorexidina e timol. Os grupos 3 e 4 foram armazenados em água por 7 dias e 30 dias, respectivamente, enquanto os corpos de prova do grupo 2 foram, logo depois da colagem, colocados em ágar semeado com Streptococcus mutans por $48 \mathrm{~h}$ a $37^{\circ} \mathrm{C}$. Resultados: os grupos experimentais, com exceção do grupo controle, apresentaram atividade antimicrobiana com tendência de redução do seu potencial de ação com maior tempo de imersão em água. Conclusão: a associação do verniz de clorexidina a um sistema adesivo utilizado em Ortodontia apresenta-se vantajosa pela sua atividade antimicrobiana.
\end{abstract}

Palavras-chave: Clorexidina. Adesivos. Agentes antimicrobianos.

\section{INTRODUÇÃO}

Atualmente, a utilização de aparelhos ortodônticos fixos está bastante difundida. Contudo, esses aparelhos associam-se a dificuldades de higienização. Durante a terapêutica, são criadas áreas retentivas que favorecem o acúmulo de biofilme e o crescimento bacteriano. Uma das grandes dificuldades evidenciadas na Ortodontia tem sido a manutenção de uma correta higienização bucal durante o tratamento. A presença de braquetes, bandas e demais acessórios funciona como retentores adicionais de biofilme dentário, podendo levar a gengivites e desmineralizações do esmalte, causando manchas brancas e cáries dentárias ${ }^{8}$.

Estudos microbiológicos têm determinado que, após a colocação do aparelho ortodôntico fixo, ocorrem aumentos significativos do número de bactérias, principalmente lactobacilos e estreptococos, sujeitando o ambiente bucal a um desequilíbrio e possibilitando o aparecimento de doenças. Embora o biofilme dentário seja constituído por numerosas espécies de bactérias, acredita-se no envolvimento do Streptococcus mutans no desenvolvimento inicial das lesões de cárie ${ }^{20}$.

* Pós-graduada pelo Centro de Ortodontia e Ortopedia Facial Prof. José Édimo Soares Martins - UFBA

** Mestre em Clínica Odontológica pela UFBA. Professor do Curso de Especialização em Ortodontia da UFBA.

*** Professora do Departamento de Microbiologia Oral da USP.

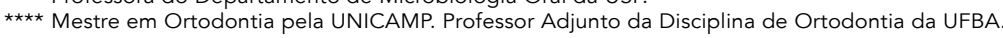


Assim, o sucesso do tratamento ortodôntico está em corrigir a oclusão da maneira mais satisfatória possível, sem, contudo, alterar a higidez preexistente dos dentes e tecidos de suporte. Caso contrário, os benefícios do tratamento podem ser questionados ${ }^{30}$. A prática ortodôntica está em constante avanço no uso de novas técnicas e materiais que beneficiem tanto o paciente quanto o profissional ${ }^{2}$. Tentativas de inibir o desenvolvimento de lesões cariosas em pacientes ortodônticos têm sido focadas no controle do biofilme bacteriano ao redor dos braquetes ${ }^{8}$. Durante a terapia, a prevenção da cárie é de responsabilidade, também, do ortodontista ${ }^{30}$.

No intuito de reduzir o aparecimento de áreas de descalcificação ao redor dos braquetes, autores têm sugerido adesivos para colagem ortodôntica contendo agentes antimicrobianos ou associados a esses ${ }^{2,17}$.

Em Ortodontia, materiais compósitos são geralmente utilizados para a colagem de braquetes. Esses compósitos podem agir como fonte de nutrição e agregação de bactérias oportunistas ${ }^{8}$. Hahn et al. ${ }^{13}$ concluíram que microrganismos se acumulam ao redor dos materiais restauradores. No entanto, foi relatado previamente que compósitos não apresentam atividade antibacteriana após a polimerização ${ }^{6}$. Dessa forma, seria oportuno modificar os materiais já utilizados, para apresentarem função adicional. Haja vista que esses materiais já estariam presentes na boca, eles poderiam servir como reservatórios ou como plataformas de dispersão de agentes terapêuticos ${ }^{21}$.

De acordo com Korbmacher et al. ${ }^{17}$, sistemas de colagem ortodônticos que liberam agentes antimicrobianos para as áreas adjacentes são úteis, pois reduzem a necessidade de colaboração e apresentam potencial de reduzir a descalcificação.

De forma a prover atividade antibacteriana aos compósitos, foi sugerido incorporar clorexidina às resinas. A clorexidina é uma clorofenilbiguanida catiônica com propriedades antimicrobianas e afinidade pelas estruturas bucais. Sua atividade bactericida se dá através da coagulação do citoplasma bacteriano, com posterior rompimento da membrana celular ${ }^{24}$. Esse agente é considerado o "padrão-ouro", em comparação às demais substâncias desenvolvidas, por agir sobre a formação do biofilme e desenvolvimento da gengivite ${ }^{3}$. Seu espectro de ação é amplo, abrangendo bactérias Gram-positivas e Gram-negativas, leveduras, dermatófilos e alguns vírus lipofílicos, além de seu efeito seletivo sobre o Streptococcus mutans ${ }^{25}$.

Contudo, as resinas compostas são consideradas clinicamente insolúveis, tendo os componentes aprisionados no seu interior dificuldade de ser liberados, pois os componentes resinosos limitam esse deslocamento ${ }^{6}$. Ribeiro e Ericson ${ }^{22}$, no entanto, observaram atividade antimicrobiana na associação da resina composta com a clorexidina, pela liberação do componente antimicrobiano, mas essa ação diminuiu com o tempo. Ehara et al. ${ }^{10}$, contudo, concluíram que resinas que liberam o agente bactericida apresentam a desvantagem de seu efeito ser transitório e se reduzir ao longo do tempo, além de comprometerem as propriedades mecânicas e apresentarem potencial tóxico para a saúde ${ }^{9}$.

Bishara et al. ${ }^{1}$ e Damon et al. ${ }^{7}$ concluíram que a associação da clorexidina a adesivos ortodônticos resultou em resistência ao cisalhamento satisfatória para utilização em Ortodontia, desde que o verniz seja pré-misturado ao adesivo, aplicado ao esmalte condicionado e fotopolimerizado. Karaman e Uysal 15 concordaram, afirmando que a resistência ao cisalhamento tornou-se clinicamente aceitável quando o verniz foi misturado ao adesivo na proporção de 2:1, respectivamente.

A associação dos materiais ortodônticos de colagem à clorexidina é interessante por ser um método coadjuvante na prevenção do aparecimento de lesões de manchas brancas e cárie ao redor dos braquetes. Isso poderá significar uma ferramenta auxiliar importante na prevenção à desmineralização da superfície do esmalte dentário, preservando as unidades dentárias ao longo do tratamento ortodôntico. 
O objetivo deste trabalho é avaliar a atividade antimicrobiana da associação de um adesivo ortodôntico com um verniz de clorexidina e timol.

\section{MATERIAL E MÉTODOS}

Realizou-se um estudo laboratorial, experimental e transversal onde foram utilizados 32 prémolares humanos, com faces vestibulares hígidas, extraídos por indicações ortodônticas.

Para a realização da presente pesquisa, foi utilizada a técnica de cultivo para verificação da inibição do crescimento bacteriano descrita por Ribei$\mathrm{ro}^{23}$, com modificações.

As faces linguais dos dentes foram aplainadas, tanto a coroa quanto a raiz, de forma que os dentes apresentaram uma largura vestibulolingual de aproximadamente $7 \mathrm{~mm}$ (Fig. 1A) e puderam ser assentados em uma superfície plana, com a face vestibular voltada para cima. Os dentes também foram desgastados em suas faces mesiais e distais de forma que apresentassem $3,8 \mathrm{~mm}$, correspondentes à largura do braquete a ser colado. A área de colagem foi delimitada por fita adesiva, de forma que apenas a área da base do braquete ficasse exposta e entrasse em contato com o material a ser avaliado. Foram, então, submetidos a um ciclo completo de esterilização em autoclave $\left(120^{\circ} \mathrm{C}\right.$ por 20 minutos). Foi feito o processo de colagem de braquetes Morelli ${ }^{\circledast}$ (Sorocaba/SP) em condições assépticas em fluxo laminar, após esterilização de todo o material de colagem clínica. $\mathrm{O}$ condicionamento ácido do centro da face vestibular com ácido fosfórico a 37\% foi feito por 15 segundos, seguido de lavagem com água apirogênica estéril e secagem do esmalte condicionado com papel de filtro estéril.

Para a colagem, foi seguido o protocolo descrito por Martinez ${ }^{18}$, que confirmou a resistência ao cisalhamento satisfatória dessa metodologia. Para o grupo 1 (controle), foi utilizado o Ortho Primer Morelli aplicado ao dente numa quantidade de $9 \mu \mathrm{L}$. Aguardou-se 30 segundos para uma leve secagem e a polimerização foi feita por 20 segundos.
Os braquetes metálicos (Morelli), já com o compósito (Transbond XT, 3M ${ }^{\circledR}, \mathrm{EUA}$ ), foram levados ao encontro do dente com o auxílio de uma pinça ortodôntica, posicionados e fotopolimerizados por 10 segundos em cada face.

Os grupos 2, 3 e 4 (Tab. 1) apresentaram a mistura de verniz de clorexidina (Cervitec, IvoclarVivadent, Suíça) com o primer (Ortho Primer Morelli) na proporção de 2:1. Essa proporção é a relatada na literatura como a que apresenta características mecânicas satisfatórias para o uso clínico em Ortodontia ${ }^{2,7,15,18,22}$, sendo $6 \mu \mathrm{L}$ do verniz e $3 \mu \mathrm{L}$ do adesivo. A mistura foi aplicada à superfície condicionada de esmalte e fotopolimerizada por 20 segundos. Os braquetes metálicos, já com o compósito, foram levados ao encontro do dente com o auxílio de uma pinça ortodôntica, posicionados e fotopolimerizados por 10 segundos em cada face (Fig. 1B). Após a colagem dos braquetes, as fitas adesivas foram removidas.

Os corpos de prova do grupo 3 foram mantidos, separadamente, em água apirogênica estéril por sete dias, em frascos hermeticamente fechados. Já os corpos de prova do grupo 4 foram mantidos, sob as mesmas condições, por 30 dias, havendo troca da água após 15 dias. Os grupos 1 e 2 foram colados e cultivados em até 4 horas após a colagem. Todos os grupos foram cultivados no mesmo momento, utilizando-se a mesma cultura bacteriana.

Com o objetivo de fixar cada corpo de prova em placa de Petri $(100 \mathrm{~mm}$ de diâmetro por $15 \mathrm{~mm}$ de altura) estéril, cerca de $40 \mathrm{~mL}$ do meio de cultura Tryptic Soy Agar (TSA, Difco Laboratories, EUA) foram distribuídos em cada uma das placas. Em seguida, cada corpo de prova foi posicionado em uma das placas, de acordo com cada grupo, com a face lingual aplainada assentada no fundo da placa. Consequentemente, as faces vestibulares permaneciam voltadas para cima, de forma que o braquete e o esmalte dentário contíguo a ele mantinham-se isentos de contato com o meio de cultura (Fig. 1C). Após a solidificação completa do 

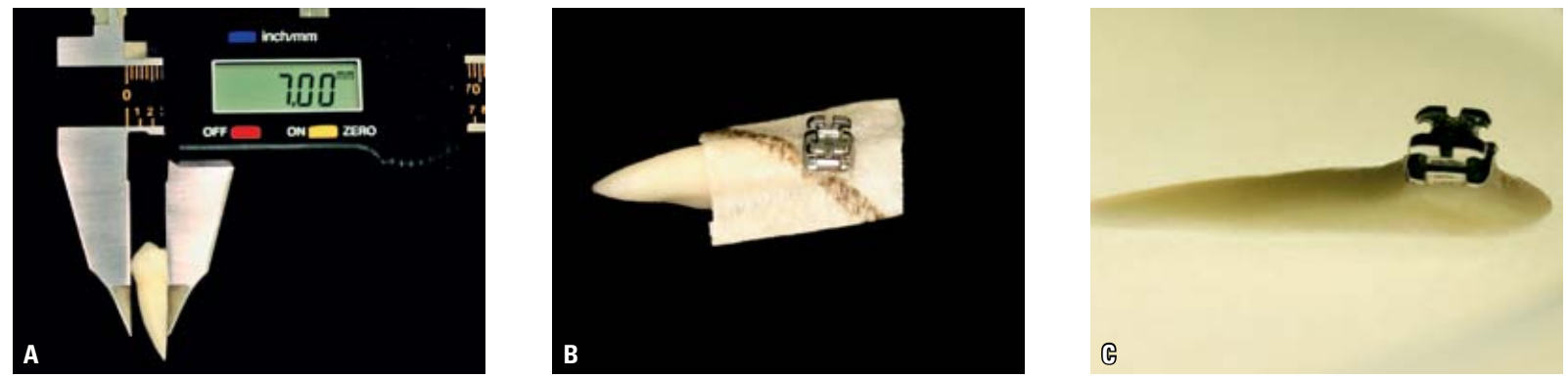

FIGURA 1 - A) Desgaste da face palatina. B) Braquete colado em área delimitada por fita adesiva. C) Dente fixado em ágar, sem contato com as aletas do braquete.

TABELA 1 - Descrição dos grupos estudados.

\begin{tabular}{cccc} 
Grupo & $\begin{array}{c}\text { Tempo de } \\
\text { armazenagem } \\
\text { em água }\end{array}$ & Adesivo & $\begin{array}{c}\text { Associação com } \\
\text { clorexidina e } \\
\text { timol (Cervitec }\end{array}$ \\
\hline 1 & - & Ortho Primer & ausente \\
\hline 2 & - & Ortho Primer & presente \\
3 & 7 dias & Ortho Primer & presente \\
4 & 30 dias & Ortho Primer & presente \\
\hline
\end{tabular}

meio, foram acrescentados cerca de $15 \mathrm{~mL}$ do mesmo meio fundido e resfriado a $50^{\circ} \mathrm{C}$, semeado com Streptococcus mutans ATCC 25175. O inóculo consistiu de uma suspensão de $8,0 \times 10^{12}$ UFC de Streptococcus mutans/mL de meio, numa densidade óptica de 1,6 em $\mathrm{DO}_{600}$, que foi distribuído nas placas contendo os corpos de prova. Cada placa recebeu quantidade de ágar com a cultura de Streptococcus mutans suficiente para recobrir a base dos braquetes e a superfície do esmalte circunjacente à área de colagem, sem recobrir as aletas. Aguardou-se a secagem do meio e, posteriormente, as placas foram incubadas em estufa bacteriológica por 48 horas a $37^{\circ} \mathrm{C}$. Após o cultivo, foi feita a leitura da presença ou ausência do halo de inibição de crescimento bacteriano. Nos casos em que houve formação de halo de inibição, foi feita a medida do diâmetro desse halo, com auxílio de compasso de pontas secas e régua milimetrada. Os resultados foram submetidos à análise estatística de variância ANOVA e ao teste de Tukey.

\section{RESULTADOS}

A análise de ANOVA comprovou diferença significativa entre os resultados obtidos entre os grupos, com $\mathrm{p}$ valor de 0,000 . O grupo controle não apresentou qualquer indício de formação de halo de inibição. Para o grupo 2, a média dos valores encontrados foi de 4,125mm, com desvio-padrão de 0,991. A média de valores apresentada no grupo 3 foi de $3 \mathrm{~mm}$, com desvio-padrão de 0,756 . Para o grupo 4, a média dos valores apresentados foi de 2,625mm, com desvio-padrão de 0,518 (Tab. 2). Verificou-se diferença estatisticamente significativa entre os resultados obtidos no grupo 1 e demais grupos, e entre os grupos 2 e demais grupos. Contudo, entre os grupos 3 e 4 não foi obtida diferença estatisticamente significativa, apesar de ser possivel verificar a tendência de redução nos valores apresentados, como observado no gráfico 1 .

\section{DISCUSSÃO}

Ainda não existe um método padrão-ouro para avaliação in vitro das propriedades antimicrobianas dos agentes de colagem ${ }^{26}$. Diversos estudos in vitro têm avaliado a efetividade antimicrobiana de materiais de colagem através do método de difusão em ágar ${ }^{14,16}$. O teste de difusão em ágar é um método aceitável para, inicialmente, diferenciar a atividade antimicrobiana de substâncias ${ }^{29}$. As zonas de inibição de crescimento dependem da toxicidade do material contra a bactéria testada e 
TABELA 2 - Resultados obtidos $(\mathrm{p}=0,000)$.

\begin{tabular}{ccccc} 
& Grupo 1 & Grupo 2 & Grupo 3 & Grupo 4 \\
$\begin{array}{c}\text { Média do } \\
\text { halo (mm) }\end{array}$ & 0,000 & 4,125 & 3 & 2,625 \\
d.p. & 0,000 & 0,991 & 0,756 & 0,518 \\
\hline
\end{tabular}

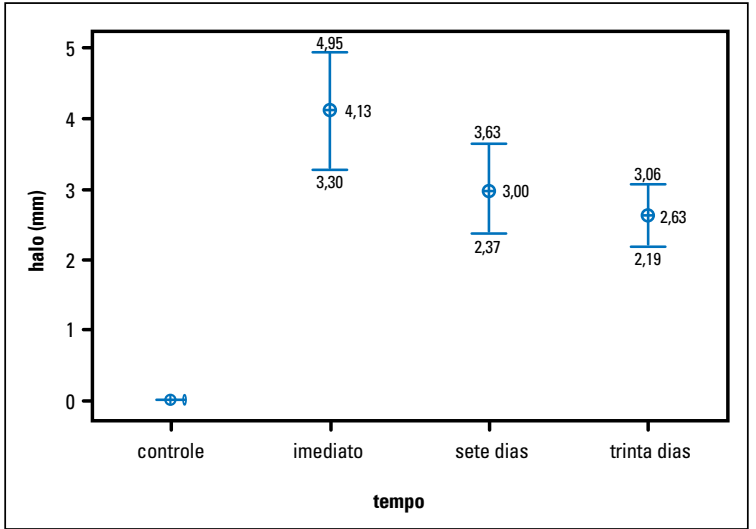

GRÁFICO 1 - Tendência de redução no halo formado, verificada a partir das médias apresentadas em cada grupo.

da difusibilidade do material pelo meio de cultura utilizado $^{11}$. Nesse estudo, foi utilizado o método de difusão em ágar para observação da atividade do agente estudado contra uma das bactérias mais comumente associadas à doença cárie: Streptococcus mutans. Essa bactéria apresenta, também, boa afinidade por resinas compostas ${ }^{19}$.

Foi utilizado o verniz Cervitec por se tratar de um composto amplamente utilizado como fonte de clorexidina em muitos estudos ${ }^{1,7,18,23}$.

Com esse estudo, foi possivel observar ação antimicrobiana da clorexidina, cuja efetividade está bastante estabelecida na Odontologia ${ }^{5}$ quando essa é associada a adesivos utilizados em Ortodontia. Contudo, mais estudos in vitro e in vivo são necessários para determinar a significância clínica e a duração das propriedades antimicrobianas sobre uma variedade de microrganismos, presentes na cavidade bucal com participação na patogenicidade do biofilme bacteriano e na doença cárie.
Assim como nos achados de Ribeiro ${ }^{23}$, verificou-se, a partir da formação de halo de inibição, que a associação do verniz de clorexidina ao adesivo ortodôntico apresenta atividade antimicrobiana ao liberar a substância antimicrobiana para o meio, inibindo, in vitro, o crescimento bacteriano nas áreas circunjacentes ao braquete. Provavelmente, foi liberada uma pequena quantidade de clorexidina da porção abaixo do braquete, pois apenas uma fina camada da associação adesivo/ verniz foi exposta ao meio ${ }^{4}$.

A redução dos efeitos da clorexidina com o tempo pode ser devida à redução na taxa de liberação ou à própria redução na quantidade de material presente. Segundo Couto Jr. et al. ${ }^{6}$, apesar da liberação do componente parecer maior inicialmente, a diminuição nessa taxa indica que os componentes da camada externa esgotam-se, ou seja, se dissolvem com a armazenagem em água. Já os componentes aprisionados no interior da massa resinosa têm grande dificuldade de se liberarem, pois os componentes resinosos limitam esse deslocamento ${ }^{6}$. Na literatura, encontram-se relatos de liberação contínua, em ambiente aquoso, de compostos localizados inicialmente no interior de adesivos resinosos ortodônticos por 115 dias $^{28}$ ou mesmo 2 anos ${ }^{12}$

Muitas vezes, os agentes terapêuticos dos biomateriais dentários são liberados desses materiais com taxa de liberação decrescente. A água da cavidade bucal se difunde dentro da matriz resinosa e o agente aprisionado pelo adesivo se dissolve e se dispersa em concentrações cada vez menores. Com o passar do tempo, o agente é liberado e extraído de uma camada da matriz cada vez mais profunda, significando que o tempo necessário para a difusão para o meio externo aumenta, enquanto a taxa de liberação diminui ${ }^{21}$. Essa pode ser também a explicação da ausência de diferença estatisticamente significativa entre a atividade antimicrobiana do grupo que ficou estocado em água por 7 dias e o grupo estocado por 30 dias.

No entanto, foi possivel verificar redução significativa da atividade antimicrobiana no grupo que 
não foi estocado em momento algum em água, em comparação ao grupo estocado por sete dias. Foi relatado que a imersão em água nas três primeiras horas faz com que 50\% dos componentes da resina sejam liberados ${ }^{27}$.

Não é possível afirmar por quanto tempo o sistema apresentará atividade antimicrobiana, principalmente em meio bucal. Percebe-se, contudo, que se trata de uma associação cujos efeitos antimicrobianos apresentam uma tendência à redução, provavelmente sendo uma fonte esgotável de clorexidina. Logo, esses benefícios não duram por todo o tratamento ortodôntico e podem haver modificações nas propriedades mecânicas após a liberação da substância. Entretanto, é provável que essa atividade abranja o período mais crítico de acúmulo de biofilme e de maiores dificuldades na realização de uma higienização bucal adequada, que corresponde à época de instalação do aparelho fixo e os quatro meses que a seguem ${ }^{20}$, justificando assim seus benefícios.

Damon et al. ${ }^{7}$ e Bishara et al. ${ }^{1}$ concluíram que a associação de verniz de clorexidina prémisturado a adesivos ortodônticos, aplicado ao esmalte condicionado e fotopolimerizado, resultou em resistência ao cisalhamento satisfatória para utilização em Ortodontia. Karaman e Uy$\mathrm{sal}^{15}$ concordaram, afirmando que a resistência ao cisalhamento tornou-se clinicamente aceitável quando o verniz foi misturado ao adesivo na proporção de 2:1, respectivamente. Ribeiro ${ }^{23}$ e Martinez ${ }^{18}$, após avaliarem a resistência adesiva de sistemas de colagem cujos adesivos foram pré-misturados ao verniz de clorexidina Cervitec, concluíram que não houve alteração estatisticamente significativa da resistência adesiva em comparação ao adesivo sozinho. Maior número de estudos é necessário para avaliar a resistência mecânica após a liberação da clorexidina, a estabilidade de cor, compatibilidade celular e tissular local e sistêmica para a utilização da associação adesivo/verniz na prática clínica diária.

\section{CONCLUSÃO}

A partir desse estudo, é possível concluir que a associação de verniz de clorexidina a um adesivo ortodôntico apresenta atividade antimicrobiana, in vitro, mesmo após a imersão do conjunto em água por sete ou trinta dias, sendo possivel perceber uma tendência de redução da ação antimicrobiana com o aumento do tempo de imersão em meio aquoso.

\title{
Evaluation of antimicrobial activity of orthodontic adhesive associated with chlorhexidine-thymol varnish in bracket bonding
}

\begin{abstract}
Objective: To assess the antimicrobial activity resulting from the association of an orthodontic adhesive with chlorhexidine-thymol varnish. Methods: Thirty-two extracted human premolars were used, divided into four groups. In Group 1, the control group, the adhesive used to bond the bracket was not associated with any antimicrobial agent. Groups 2, 3 and 4 were bonded with an adhesive system associated with chlorhexidine-thymol varnish. Groups 3 and 4 were stored in water for 7 days and 30 days, respectively, while the specimens from group 2 were, soon after bonding, placed on agar seeded with Streptococcus mutans for 48 hours, at $37^{\circ} \mathrm{C}$. Results: The experimental groups, with the exception of the control group, showed antimicrobial activity whose action tended to decline commensurately with the amount of time that they remained immersed in water. Conclusions: The association of chlorhexidine-thymol varnish with an adhesive system used in orthodontics proved to be advantageous due to its antimicrobial activity.
\end{abstract}

Keywords: Chlorhexidine. Adhesives. Antimicrobial agents. 


\section{REFERÊNCIAS}

1. Bishara SE, Vonwald L, Zamtua J, Damon PL. Effects of various methods of chlorhexidine application on shear bond strength. Am J Orthod Dentofacial Orthop. 1998 Aug;114(2):150-3.

2. Bishara SE, Damon PL, Olsen ME, Jakobsen JR. Effect of applying chlorhexidine antibacterial agent on the shear bond strength of orthodontic brackets. Angle Orthod. 1996;66(4):313-6.

3. Bowen WH. Wither or whither caries research? Caries Res. 1999;33(1):1-3.

4. Chan DC, Swift EJ Jr, Bishara SE. In vitro evaluation of a fluoride-releasing orthodontic resin. J Dent Res. 1990 Sep;69(9):1576-9.

5. Cleghorn B, Bowden $\mathrm{GH}$. The effect of $\mathrm{pH}$ on the sensitivity of species of Lactobacillus to chlorhexidine and the antibiotics minocycline and spiramycin. J Dent Res. 1989 Jul;68(7):1146-50

6. Couto MP Jr, Nagem H Filho, Nagem HD, Couto MGP. Determinação da taxa de flúor liberado por cinco resinas compostas. Rev Facul Odontol Bauru. 2000 janjun;8(1/2):65-69.

7. Damon PL, Bishara SE, Olsen ME, Jakobsen JR. Bond strength following the application of chlorhexidine on etched enamel. Angle Orthod. 1997;67(3):169-72.

8. Derks A, Katsaros C, Frencken JE, van't Hof MA, KuijpersJagtman AM. Caries-inhibiting effect of preventive measures during orthodontic treatment with fixed appliances. Caries Res. 2004 Sep-Oct;38(5):413-20.

9. Ebi N, Imazato S, Noiri Y, Ebisu S. Inhibitory effects of resin composite containing bactericide-immobilized filler on plaque accumulation. Dent Mater. 2001 Nov; 17(6):485-91.

10. Ehara A, Torii M, Imazato S, Ebisu S. Antibacterial activities and release kinetics of a newly developed recoverable controlled agent-release system. J Dent Res. 2000 Mar;79(3):824-8.

11. Estrela C, Estrela CRA, Moura J, Bammann LL. Testing calcium hydroxide antimicrobial potential by different methods. J Dent Res. 2000;79:529 (IADR Abstract 3081).

12. Ferracane JL, Condon JR. Rate of elution of leachable components from composite. Dent Mater. 1990 Oct;6(4):282-7.

13. Hahn R, Weiger R, Netuschil L, Brüch M. Microbial accumulation and vitality on different restorative materials. Dent Mater. 1993 Sep;9(5):312-6.

14. Herrera M, Carrión P, Bravo M, Castillo A. Antibacterial activity of four dentin bonding systems. Int J Antimicrob Agents. 2000 Aug;15(4):305-9.

15. Karaman Al, Uysal T. Effectiveness of a hydrophilic primer when different antimicrobial agents are mixed. Angle Orthod. 2004 Jun;74(3):414-9.

16. Karanika-Kouma A, Dionysopoulos P, Koliniotou-Koubia E, Kolokotronis A. Antibacterial properties of dentin bonding systems, polyacid-modified composite resins and composite resins. J Oral Rehabil. 2001 Feb;28(2):157-60.
17. Korbmacher HM, Huck L, Kahl-Nieke B. Fluoride-releasing and antimicrobial self-etching primer effects on the shear bond strength of orthodontic brackets. Angle Orthod. 2006 Sep;76(5):845-50.

18. Martinez TP. Avaliação da resistência ao cisalhamento de bráquetes, colados com sistemas adesivos associados a diferentes agentes antimicrobianos. [dissertação]. Salvador (BA).Faculdade de Odontologia, Universidade Federal da Bahia; 2006

19. Pedrini D, Gaetti-Jardim E Jr, Vasconcelos AC. Retention of oral microorganisms on conventional and resin-modified glass-ionomer cements. Pesqui Odontol Bras. 2001 julset;15(3):196-200.

20. Petersson LG, Maki Y, Twetman S, Edwardsson S. Mutans streptococci in saliva and interdental spaces after topical applications of an antibacterial varnish in school children. Oral Microbiol Immunol. 1991 Oct;6(5):284-7.

21. Rawls HR. Preventive dental materials: sustained delivery of fluoride and other therapeutic agents. Adv Dent Res. 1991 Dec;5:50-5.

22. Ribeiro J, Ericson D. In vitro antibacterial effect of chlorhexidine added to glass-ionomer cements. Scand J Dent Res. $1991 \mathrm{Dec} ; 99(6): 533-40$

23. Ribeiro JLO. Avaliação da resistência adesiva e da atividade antimicrobiana de diferentes sistemas de colagem de bráquetes associados à clorexidina e ao flúor. [dissertação]. Salvador (BA): Universidade Federal da Bahia; 2006

24. van Rijkom HM, Truin GJ, van 't Hof MA. A meta-analysis of clinical studies on the caries-inhibiting effect of chlorhexidine treatment. J Dent Res. 1996 Feb;75(2):790-5.

25. Rosa OPS, Rocha RSS. Clorexidina e cárie dentária. CECADE News. 1993 jan-ago;1(1/2):1-24.

26. Schmidlin OA, Zehnder M, Schmidlin PR. Effectiveness of dentine bonding agents against cariogenic bacteria in vitro: a comparison of two methods. Oral Microbiol Immunol. 2003 Jun;18(3):140-3.

27. Tanaka K, Taira M, Shintani H, Wakasa K, Yamaki M. Residual monomers (TEGDMA and Bis-GMA) of a set visible-lightcured dental composite resin when immersed in water. J Oral Rehabil. $1991 \mathrm{Jul} ; 18(4): 353-62$

28. Thompson LR, Miller EG, Bowles WH. Leaching of unpolymerized materials from orthodontic bonding resin. J Dent Res. 1982 Aug;61(8):989-92.

29. Tobias RS. Antibacterial properties of dental restorative materials: a review. Int Endod J. 1988 Mar;21(2):155-60.

30. Zimmer BW, Rottwinkel Y. Assessing patient-specific decalcification risk in fixed orthodontic treatment and its impact on prophylactic procedures. Am J Orthod Dentofacial Orthop. 2004 Sep;126(3):318-24
Enviado em: agosto de 2008 Revisado e aceito: novembro de 2008

Endereço para correspondência Carolina Freire de Carvalho Calabrich Av. Araújo Pinho, $n^{\circ}$ 62, $7^{\circ}$ andar, Canela CEP: 40.110-912 - Salvador/BA E-mail: carolinacalabrich@yahoo.com.br 